\title{
Responsiveness of the International Classification of Functioning, Disability and Health (ICF) Core Set for rheumatoid arthritis
}

\author{
T Uhlig, ${ }^{1}$ R Moe, ${ }^{1}$ S Reinsberg, ${ }^{1}$ T K Kvien, ${ }^{1}$ A Cieza, ${ }^{2}$ G Stucki ${ }^{2}$
}

\begin{abstract}
- Additional data
(Supplementary table 1) are published online only at http:// ard.bmj.com/content/vol68/ issue6

${ }^{1}$ National Resource Center for Rehabilitation in Rheumatology, Department of Rheumatology, Diakonhjemmet Hospital, Oslo, Norway; ${ }^{2}$ Physical Medicine and Rehabilitation, University of Munich, Munich, Germany
\end{abstract}

Correspondence to:

Dr T Uhlig, National Resource

Center for Rehabilitation in

Rheumatology, Department of

Rheumatology, Diakonhjemmet Hospital, Postboks 23 Vinderen,

N-0319 Oslo, Norway;

till.uhlig@diakonsyk.no

Accepted 5 July 2008

Published Online First

14 July 2008

\begin{abstract}
Background: The comprehensive International

Classification of Functioning, Disability and Health (ICF)

Core Set for rheumatoid arthritis (RA) is a selection of 96 categories from the ICF, representing relevant aspects in the functioning of patients with RA.

Objectives: To study the responsiveness of the ICF Core
\end{abstract} Set for RA in rheumatological practice.

Methods: A total of 46 patients with RA ( $72 \%$ women, mean (SD) age 53.6 (12.6) years, disease duration 6.3 (8.0) years) were interviewed at baseline and again after 6 months treatment with a disease-modifying antirheumatic drug (DMARD), applying the ICF Core Set for RA with qualifiers for problems on a modified three-point scale (no problem, mild/moderate, severe/complete). Patient-reported outcomes included Modified Health Assessment Questionnaire (MHAO) and Short-Form 36 (SF-36) health survey, and disease activity was calculated. Responsiveness was measured as change in qualifiers in ICF categories, and was also compared with change in patient-reported outcomes.

Results: After 6 months of DMARD treatment, improvement by at least one qualifier was seen in $20 \%$ of patients (averaged across all ICF categories), 71\% experienced no change and $9 \%$ experienced worsening symptoms. Findings were similar across the different aspects of functioning. Mainly moderate effect sizes were seen for 6-month changes in the ICF Core Set for RA, especially in patients with improved health status, with similar effect size for disease activity. The components in the ICF Core Set for RA were only weakly associated with patient-reported outcomes and disease activity.

Conclusions: The ICF Core Set for RA demonstrated moderate responsiveness in this real-life setting of patients where minor changes occurred during treatment with DMARDs.

Rheumatoid arthritis (RA) is a chronic disabling disease which is often associated with limitations in physical, mental and social function, ${ }^{12}$ and with work disability. ${ }^{3}$ The framework of the World Health Organization (WHO) International Classification of Functioning, Disability and Health (ICF) can be used to describe and assess daily functioning and disability from a biopsychosocial perspective in all aspects of health. This framework for the description of health and health-related conditions ${ }^{5}$ includes the components Body Functions and Structures, Activities and Participation, Environmental Factors and Personal Factors. Components are further defined by the socalled ICF categories. To rate the magnitude or the severity of the problem in each of the ICF categories, the WHO has proposed a so-called qualifiers' scale, which is scored by a health professional during a patient interview.

In order to facilitate the application of the ICF in clinical practice, specific Core Sets were developed for specific diseases as shortlists of ICF categories, which are important for patients. The comprehensive ICF Core Set for RA represents the typical spectrum in functioning of patients with RA with a selection of 96 categories $^{6}$ in the 4 components of Body Functions (b), Body Structures (s), Activities and Participation (d) and Environmental Factors (e), ${ }^{6}$ and this core set was developed by experts in a formal decision-making and consensus process based on evidence of preliminary studies.

The introduction of the ICF had a positive effect on staff satisfaction with multidisciplinary team care in a day patient setting ${ }^{7}$ and on satisfaction among patients with RA. ${ }^{8}$ The ICF has recently shown validity against therapist formulated goals in patients with RA. ${ }^{9}$ The present ICF Core Set for RA has also been validated from the patient perspective. ${ }^{10} 11$

The development of ICF Core Sets with qualifiers raises the questions of reliability, validity and also responsiveness when applied in clinical practice, since the use of qualifiers opens the possibility of registering change over time. Thus, in spite of the ambiguity of how to use the ICF, the exploration of responsiveness is necessary to draw conclusions on psychometric properties, longitudinal validity and future development of the qualifiers in patient populations. ${ }^{12}$

The ICF Core Set for RA has recently demonstrated low to moderate reliability, ${ }^{13}$ but exploratory examination of the qualifiers' scale of the ICF Core Set for RA also suggested better feasibility and higher reliability when the number of qualifiers was reduced to three for all ICF categories. ${ }^{13}$ Validation has not yet been performed in a longitudinal setting and especially not in a real-life setting where less changes are expected during treatment of RA opposed to randomised clinical trials.

This study had the objective of examining the responsiveness of the ICF Core Set for RA in patients who were given disease-modifying antirheumatic drugs (DMARDs) in a real-life setting. Changes in ICF were also related to changes in established patient-reported outcomes and disease activity.

\section{PATIENTS AND METHODS}

\section{Study design}

We conducted a responsiveness study with assessments at two time points 6 months apart in patients with RA starting with DMARD treatment. 


\section{Patients}

A sample of 61 home-dwelling patients diagnosed with $\mathrm{RA}^{14}$ by their treating rheumatologist were included in the study after written informed consent was obtained. Patients were recruited consecutively from the rheumatology outpatient department at the Diakonhjemmet Hospital in Oslo, Norway where they, as a routine part of a DMARD prescription, are included into the NOR-DMARD project which is a follow-up study after DMARD prescription. ${ }^{15}$ After 6 months, 46 patients had completed the study with all assessments and were eligible for the present analyses.

\section{Data collection}

Patients were interviewed twice, at the first time point (T1) and again after 6 months (mean 191 days) (second time point (T2)). Interviews at T1 and T2 were performed by the same examiner, either by an occupational therapist $(S R, n=29)$ or a physiotherapist (RHM, $\mathrm{n}=17$ ) not involved in the clinical treatment of the patients. The interviews were scheduled separately from the appointments for clinical treatment at the outpatient department. Both interviewers had reviewed ICF Core Set instruction and were trained according to a video issued by the ICF branch of the WHO.

The assessors rated during the interview the magnitude or the severity of the problem in each of the ICF categories, going one by one through all ICF categories and using all obtained information.

\section{Measures \\ Demographics and medical treatment}

At baseline, age, gender, disease duration in years, level of education ( $\leqslant 12$ years/ $>12$ years), presence of erosions and rheumatoid factor (RF) were recorded. Use of the following drugs at baseline was recorded (yes/no): non-steroidal antirheumatic drugs, cyclo-oxygenase 2 inhibitors and glucocorticoids. The DMARD that was initiated at baseline was recorded as monotherapy (predominantly methotrexate), combination of conventional DMARDs, or biological drug.

\section{ICF Core Set for RA}

The ICF Core Set for RA includes 25 categories from the component body functions, 18 from the component Body Structures, 32 from the component Activities and Participation and 21 from the component Environmental Factors. ${ }^{6}$ The severity of a patient's problem in each of the ICF categories is quantified with the qualifier scale, which for the components Body Functions and Structures, and Activities and Participation originally had five response levels, each ranging from 0 to 4 , corresponding to no/mild/moderate/severe/complete impairment. For example, a moderate problem with walking would give a score of 2 . The qualifier scale of the component Environmental Factors originally had nine response levels indicating four degrees of a possible barrier, one level representing no influence and four degrees of a possible facilitator.

Based on previous findings of improved reliability and feasibility with fewer response levels, ${ }^{13}$ we applied three response levels for the qualifier: no impairment (0), mild or moderate impairment (1) and severe or complete impairment (2). Environmental factors were also graded with three response levels: being a barrier (-1), having no influence (0) or being a facilitator (+1). Additional response options for ICF categories were "not specified" and "not applicable" for each ICF category.

\section{Patient-reported outcomes}

Patients filled in self-administered questionnaires at baseline and after 6 months as part of the protocol assessment in the NOR-DMARD project. ${ }^{15}$ The results from these questionnaires were not accessible to the assessors during the ICF interviews.

Measures at these two time points included pain, fatigue and patient global assessment of disease activity (all 0-100 mm visual analogue scales), Modified Health Assessment Questionnaire (MHAQ) ${ }^{16}$ and the Short-Form 36 (SF-36) health survey. ${ }^{17}$ Physical and mental component summary scores (PCS and MCS, respectively) were aggregated from the SF-36. ${ }^{18}$ The utility measure (SF-6D) was derived from the responses to the SF-36 questionnaire based on an algorithm developed by Brazier. ${ }^{19}$

A health transition item was used as external indicator of improvement with the question: "Has your overall health improved since the start of the study?" with response options "yes/no".

\section{Disease activity}

A total of 28 swollen and tender joint counts were performed and the 28-joint Disease Activity Score (DAS28) was calculated from joint counts, patient global assessment and erythrocyte sedimentation rate. ${ }^{20}$ Achievement of European league Against Rheumatism (EULAR) moderate response ${ }^{21}$ was assessed after 6 months.

\section{Data analysis and statistics}

Descriptive statistics and distribution with frequencies and proportions were used to describe ICF categories, demographics and clinical characteristics. For categorical variables we used counts with percentages, continuous data are presented as means with standard deviations (SD). A paired Student t test was applied to examine improvement of continuous health status or disease activity measures.

We examined internal and external responsiveness. ${ }^{22}$ To examine internal responsiveness of the individual ICF categories we calculated the percentage of patients improving in functioning by one or two response levels, remaining unchanged or worsening by one or two response levels. We defined a clinically relevant change in an individual ICF category when after 6 months DMARD treatment the response level was scored at least one level better or worse.

We also summed up in each patient the number of all qualifier changes in the 96 categories of the ICF Core Set for RA (number of qualifiers with improvement minus number of qualifiers with worsening) and in each functioning component. Changes in ICF components, patient-reported outcomes and disease activity among patients with and without improvement in health were calculated as a measure for effect size as standardised response means (change over 6 months/SD of the change). We applied Cohen standards for effect sizes ${ }^{23}$ as: small effect 0.2 , medium effect 0.5 and large effect 0.8 , and presented them together with $p$ values from the unpaired Student $t$ test as recommended. ${ }^{24}$

For examination of external responsiveness of the ICF during DMARD treatment we also compared changes in ICF components and overall in the ICF Core Set for RA with 6-month changes in health status instruments (MHAQ, SF-36), SF-6D and disease activity (DAS28), using Spearman rho correlation coefficients. The use of a transition item for improvement facilitates interpretation of the discriminative ability. ${ }^{25}$ 
A correlation coefficient below 0.40 was considered to indicate a low correlation and a value of 0.40 to 0.59 a moderate correlation.

The level of significance was set to $p<0.05$. All statistical analyses were performed using SPSS V. 14.0 statistical software (SPSS Inc, Chicago, IL, USA). The regional ethics committee approved the study.

\section{RESULTS}

Demographic data and clinical characteristics of the participants are shown in table 1 for completers $(n=46)$ and non-completers $(\mathrm{n}=15)$. Reasons for non-completion were declination or practical difficulty to meet for a new scheduled ICF interview $(\mathrm{n}=12)$ in addition to the clinical routine follow-up visit and lack of clinical data when the specific DMARD regime was terminated $(n=3)$ before 6 months follow-up.

The health transition item indicated that the majority of the patients considered their health improved (27 of 46, 59\%) after 6 months with DMARD treatment.

For all individual ICF categories with baseline values for impairment and 6-month changes in the different components Body Functions, Body Structures and Activities and Participation, and Environmental Factors, see Supplementary material. The two most responsive individual categories in this study were s73011 "Wrist joint" and e115 "Products and technology for personal use in daily living" where 58\% of patients had improved and $43 \%$ had obtained more support, respectively, over 6 months (Supplementary material). Of 46 patients, no problems in any of the component categories at baseline were present for 0 patients for Body Functions, for 1 patient for Body Structures, for 1 patient for Activities and Participation and for 5 patients for Environmental Factors.

Table 1 Demographic characteristics and baseline scores for health status measures and disease activity in completers and non-completers (means (SD) for continuous variables, \% for counts)

\begin{tabular}{lcc}
\hline & $\begin{array}{c}\text { Completers } \\
(\mathbf{n}=\mathbf{4 6})\end{array}$ & $\begin{array}{c}\text { Non-completers } \\
(\mathbf{n}=\mathbf{1 5})\end{array}$ \\
\hline Age (years) & $53.6(12.6)$ & $53.3(10.7)$ \\
Female & $72 \%$ & $53 \%$ \\
Disease duration (years) & $6.3(8.0)$ & $6.1(8.9)$ \\
Rheumatoid factor positive & $80 \%$ & $87 \%$ \\
Erosive disease (present) & $50 \%$ & $47 \%$ \\
Education level high (>12 years) & $43 \%$ & $40 \%$ \\
Pain (100 mm VAS) & $47(23)$ & $40(23)$ \\
Fatigue (0-100 mm VAS) & $52(29)$ & $37(27)$ \\
Patient global (0-100 mm VAS) & $52(25)$ & $39(22)$ \\
MHA0 (1-4) & $1.7(0.5)$ & $1.6(0.5)$ \\
SF-36 PCS (0-100) & $30(9.9)$ & $35(6.6)$ \\
SF-36 MCS (0-100) & $45(11.0)$ & $49(8.5)$ \\
DAS28 & $5.1(1.3)$ & $4.2(1.3)$ \\
Glucocorticoids (current use) & $57 \%$ & $73 \%$ \\
NSAID (current use) & $29 \%$ & $27 \%$ \\
Cyclo-0xygenase 2 inhibitors (current & $5 \%$ & $7 \%$ \\
use) & & \\
DMARD initiated at baseline: & $65 \%$ & $13 \%$ \\
Monotherapy & $11 \%$ & \\
Combination & $24 \%$ & \\
Biological agent & & \\
\hline
\end{tabular}

DAS28, 28-joint Disease Activity Score; MCS, mental component summary; MHAQ, Modified Health Assessment Questionnaire; NSAID, non-steroidal antirheumatic drug; PCS, physical component summary; SF-36, Short Form 36; VAS, visual analogue scale.
Table 2 displays the mean number with range for impairments present for patients at baseline and follow-up and presents mean frequency of patients improving, staying unchanged and worsening in the different ICF components and overall for all 96 categories in the ICF Core Set for RA. In all, $20 \%$ of patients had improvement with at least one response level averaged through all ICF categories, $71 \%$ experienced no change and $9 \%$ worsening. Findings for change in ICF categories were consistent through the four components of functioning.

Mean changes and effect sizes for ICF components of functioning and for measures for patient-reported outcomes and disease activity and utility are presented in table 3 for all patients, and for patients with and without overall improvement over 6 months. During the 6-month treatment period disease activity (DAS28) improved within the patient group with mean (SD) $0.58(0.77)(p<0.001$, paired t test). Physical function improved within the whole patient group by mean $0.16(0.46)(p=0.01)$ for MHAQ and mean $3.5(8.7)(p=0.02)$ for SF-36 PCS, whereas mental function (SF-36 MCS) improved by mean $4.2(11.0)(p=0.02)$ and SF-36 derived utility by 0.07 (0.12) $(p=0.001)$ (table 3$)$.

The mean sum of qualifier changes in the ICF Core Set in RA was numerically, but not statistically significantly, higher in improved versus non-improved patients without improved health (13.9 vs 7.0, $p=0.08$ ) (table 3 ). Similar patterns were observed in the different domains of functioning, but were statistically significant only for the component Body Functions (table 3). Effect sizes were moderate for three ICF components, were small for one component and were higher for patients with improvement than for non-improved patients. Effect sizes for changes in the ICF Core Set in RA (0.83) and for disease activity $(0.75)$ were moderate to high and were comparable (table 3).

Correlation coefficients between changes in ICF categories and changes in patient-reported health status, utility and disease activity are displayed in table 4. Patients were also examined separately dependent on whether they considered their health status improved or not according to the transition question. We found only low correlation between changes in ICF components and patient-reported outcomes, utility and disease activity with statistical significance for the association between disease activity and ICF components, however with the exception of Environmental Factors (table 4).

\section{DISCUSSION}

This study is the first to examine how ICF categories change during treatment of RA. Over 6 months treatment with DMARD on average $20 \%$ of patients had improvement by one or two qualifiers through all 96 categories contained in the ICF Core Set for RA. The majority of patients remained unchanged however and a worsening of functioning was present overall in $9 \%$ of patients. Interestingly, the specified problems with functioning changed consistently through all components Body Functions and Structures, Activities and Participation, and Environmental Factors.

Our examination of external responsiveness comparing the ICF to established health status instruments showed very low correlation coefficients and no consistent and convincing results. Mainly moderate effect sizes were observed during DMARD treatment in the different ICF components, but were comparable with patient-reported outcomes and disease activity. Between improved and non-improved patients statistically significant changes were only observed for Body Functions, which was expected as physiological functions rather than 
Table 2 Mean number (range) of categories with impairments at baseline and follow-up by International Classification of Functioning, Disability and Health (ICF) Core Set for rheumatoid arthritis (RA) component and proportions of patients (\%) with impairment changes over 6 months in components

\begin{tabular}{|c|c|c|c|c|c|c|c|}
\hline & \multirow{2}{*}{$\begin{array}{l}\text { Impairments at } \\
\text { baseline (n) }\end{array}$} & \multirow{2}{*}{$\begin{array}{l}\text { Impairments at } \\
\text { follow-up (n) }\end{array}$} & \multicolumn{2}{|l|}{ Improvement } & \multirow{2}{*}{$\begin{array}{l}\text { Unchanged } \\
0 \text { Qualifiers }\end{array}$} & \multicolumn{2}{|l|}{ Worsening } \\
\hline & & & 2 Qualifiers & 1 Qualifier & & 1 Qualifier & 2 Qualifiers \\
\hline $\begin{array}{l}\text { Body functions } \\
(\mathrm{n}=25)\end{array}$ & 13.8 (3 to 20$)$ & 11.0 (0 to 22$)$ & $1 \%$ & $20 \%$ & $71 \%$ & $8 \%$ & $0 \%$ \\
\hline $\begin{array}{l}\text { Body structures } \\
(n=18)\end{array}$ & $8.0(0$ to 16$)$ & $6.5(0$ to 13$)$ & $1 \%$ & $18 \%$ & $73 \%$ & $8 \%$ & $0 \%$ \\
\hline $\begin{array}{l}\text { Activities and } \\
\text { participation }(n=32)\end{array}$ & 13.1 (0 to 27) & 9.2 (1 to 25$)$ & $1 \%$ & $20 \%$ & $70 \%$ & $8 \%$ & $0 \%$ \\
\hline $\begin{array}{l}\text { All categories } \\
(n=96)\end{array}$ & 38.1 (7 to 70$)$ & 28.6 (1 to 62 ) & $1 \%$ & $19 \%$ & $71 \%$ & $9 \%$ & $0 \%$ \\
\hline
\end{tabular}

anatomical structures are the target for interventions with DMARDs. The association of changes in ICF categories with measures of patient-reported outcomes, utility and disease activity was low and independent of whether patients improved. Changes in Environmental Factors were small, also leading to absence of significant correlation with changes in MHAQ and SF-36.

In real-life settings such as ours, health improvements may appear on a smaller scale than in randomised controlled trials. In our 6-month study improvements on a group level were small for health status (0.16 for MHAQ, 3.5 and 4.2 units for SF-36 PCS and MCS, respectively) and 0.58 for DAS28. These mean changes are below or around the limits for minimal clinically important changes as defined by the patient, ${ }^{26}$ for physical function, ${ }^{27}$ the SF-36 instrument, ${ }^{28}$ and correspond to a moderate response in disease activity. ${ }^{21}$ Against this background of limited improvements among patient-reported outcomes it is noteworthy that the ICF still captures small changes as observed in a real-life setting with DMARD treatment as a case in point. The intervention in our study could as such serve only as a model for minor effects, typically found in real-life practice, especially when one does not measure the exact targets of the interventions. As a consequence, every statistical exercise is blurred by the very limited true effects, and in more diseased populations of patients with RA a higher responsiveness of the ICF might be seen.

Our findings are novel results in a new field. Given the adoption of the ICF by the WHO as a classification tool for global application, extensive testing of the ICF is required. In osteoarthritis the ICF Core Set for osteoarthritis has recently been validated, ${ }^{29}$ however to date there are no published results on responsiveness of any ICF Core Sets. Recently the reliability of the ICF Core Set for RA was found to be low and at best moderate. ${ }^{13}$ As a consequence of low reliability also responsiveness will be compromised. While reliability could be improved by reducing the numbers of qualifiers from five to three, it is not clear how a higher number of qualifiers would have impacted responsiveness in this study. So far there are no other studies on responsiveness of ICF Core Sets in RA or other diseases.

The ICF was not designed as a measure of health status and we in this study do not suggest calculating ICF scores; the main objective of the ICF is to describe important aspects of health and not to measure them. Our definition of responsiveness as a change of one or more qualifiers in one respective ICF category (for example from severe to moderate impairment) has high face validity and relates to an immediate context. It has been highlighted that responsiveness should be contextualised rather than being considered a static attribute. ${ }^{30}$

A limitation of this study is that it was conducted at a single centre and our findings may not be extrapolated to other environments of patients and health professionals. Further, the reduction of the number of response levels has increased feasibility and the robustness of findings at the cost of increasing the threshold for demonstrating responsiveness. With a higher number of response levels as in the original ICF qualifier scale, higher responsiveness would most likely have

Table 3 Mean change and effect size (standardised response mean) in the International Classification of Functioning, Disability and Health (ICF) Core Set for rheumatoid arthritis (RA) components and health status, utility (Short-Form 6D (SF-6D)) and disease activity (28-joint Disease Activity Score (DAS28)) over 6 months with disease-modifying antirheumatic drug (DMARD) treatment presented for patients with and without improvement in health

\begin{tabular}{|c|c|c|c|c|c|c|c|}
\hline & \multicolumn{2}{|c|}{ All patients $(n=46)$} & \multicolumn{2}{|c|}{$\begin{array}{l}\text { Patients with improved health } \\
\text { ( } \mathrm{n}=27)\end{array}$} & \multicolumn{2}{|c|}{$\begin{array}{l}\text { Patients without improved health } \\
(\mathrm{n}=19)\end{array}$} & \multirow[b]{2}{*}{ p Value* } \\
\hline & Change & Effect size & Change & Effect size & Change & Effect size & \\
\hline ICF: Body Functions & $-3.1(5.3)$ & 0.59 & $-4.5(5.0)$ & 0.85 & $-1.2(5.2)$ & 0.22 & 0.03 \\
\hline ICF: Body Structures & $-1.8(4.5)$ & 0.41 & $-2.3(4.1)$ & 0.50 & $-1.3(5.1)$ & 0.27 & 0.47 \\
\hline ICF: Activities and Participation & $-4.3(6.0)$ & 0.71 & $-5.1(6.7)$ & 0.85 & $-3.1(4.8)$ & 0.51 & 0.27 \\
\hline ICF: Environmental Factors & $-1.8(3.3)$ & 0.53 & $-2.0(3.6)$ & 0.59 & $-1.5(3.0)$ & 0.44 & 0.63 \\
\hline All ICF categories & $-11.0(13.2)$ & 0.83 & $-13.9(13.5)$ & 1.05 & $-7.0(11.9)$ & 0.53 & 0.08 \\
\hline MHAO & $-0.16(0.46)$ & 0.35 & $-0.28(0.43)$ & 0.60 & $0.01(0.45)$ & 0.01 & 0.04 \\
\hline SF-36 PCS & $3.5(8.7)$ & 0.41 & $6.4(7.9)$ & 0.74 & $0.3(8.6)$ & 0.03 & 0.01 \\
\hline SF-36 MCS & $4.2(11.0)$ & 0.38 & $5.1(10.0)$ & 0.46 & $3.0(12.2)$ & 0.28 & 0.55 \\
\hline SF-6D & $0.07(0.12)$ & 0.56 & $0.09(0.12)$ & 0.75 & $0.04(0.12)$ & 0.32 & 0.17 \\
\hline DAS28 & $-0.58(0.77)$ & 0.75 & $-0.80(0.85)$ & 1.04 & $-0.27(0.53)$ & 0.34 & 0.01 \\
\hline
\end{tabular}

*t Test comparing patients with improved versus patients without improved health.

MCS, mental component summary; MHAQ, Modified Health Assessment Questionnaire; PCS, physical component summary; SF-36, Short Form 36. 


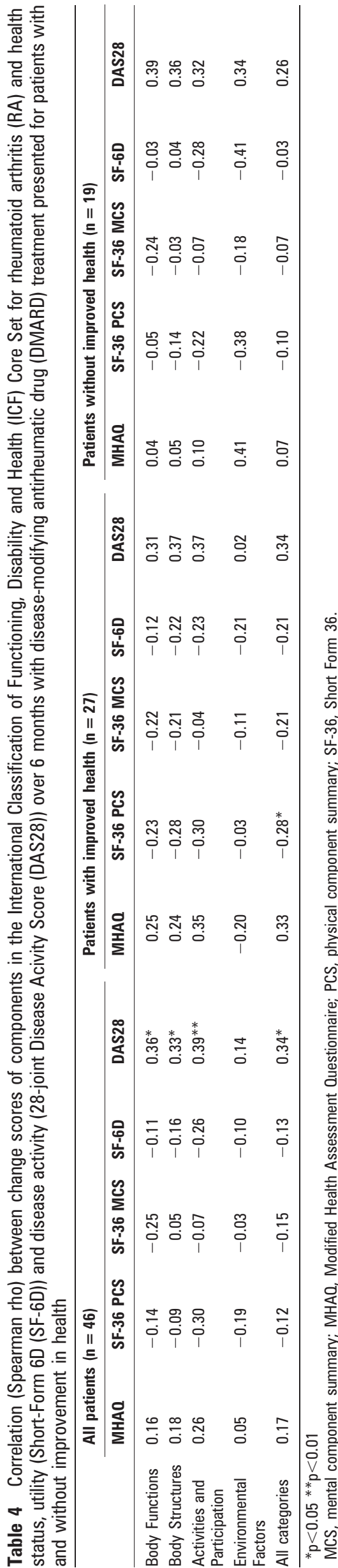

been demonstrated. A transition item may be more useful for validation and exploring interpretability of an instrument than for definition of responsiveness. ${ }^{31}$

A strength of this study is examination of patients with RA in need of medical treatment in a longitudinal setting from clinical practice. This adds external validity to our findings. Patients in our sample represent the typical average age group of patients with RA in our outpatient clinic, ${ }^{32}$ which provides rheumatology services to the population of Oslo, Norway. Both assessors in this study were experienced clinicians with extensive experience with the ICF concept.

In conclusion, this study demonstrates moderate responsiveness of the ICF RA Core Set in patients with RA who were treated in a real-life setting where smaller changes in patientreported outcomes are observed than in recent randomised controlled trial with biological drugs. ${ }^{33}$ The importance of further testing of the ICF Core Set for RA is apparent as the ICF has been adopted by the WHO, and in particular before applicability of the ICF in clinical rheumatology is considered. The ICF is an ongoing process, where testing from clinical settings such as ours and suggestions for further improvement-including testing of self-report questionnaires - continuously needs to be addressed.

Acknowledgements: The authors thank all patients who participated in the study. Funding: This project is part of the ICF Core Sets Validation Study and was supported by a research grant from the European League Against Rheumatism (EULAR).

Competing interests: TKK: Hans Bijlsma was the Handling Editor for this article. Ethics approval: The regional ethics committee approved the study.

\section{REFERENCES}

1. Uhlig T, Kvien TK, Glennås A, Smedstad LM, Førre Ø. The incidence and severity of rheumatoid arthritis. Results from a county register in Oslo, Norway. J Rheumatol 1998;25:1078-84.

2. Wolfe F. A reappraisal of $\mathrm{HAQ}$ disability in rheumatoid arthritis. Arthritis Rheum 2000;43:2751-61.

3. Sokka T, Kautiainen $H$, Mottonen $T$, Hannonen P. Work disability in rheumatoid arthritis 10 years after the diagnosis. J Rheumatol 1999;26:1681-5.

4. Ødegård S, Kvien TK, Finset A, Uhlig T. Physical and psychological predictors for word disability over seven years in patients with rheumatoid arthritis. Scand J Rheumatol 2005;34:441-7.

5. World Health Organization. International classifacation of functioning, disability and health: ICF. Geneva, Switzerland: WHO, 2001.

6. Stucki G, Cieza A, Geyh S, Battistella L, Lloyd J, Symmons D, et al. ICF Core Sets for rheumatoid arthritis. J Rehabil Med 2004;44(Suppl):87-93.

7. Verhoef J, Toussaint PJ, Putter H, Zwetsloot-Schonk JH, Vliet Vlieland TP. The impact of introducing an ICF-based rehabilitation tool on staff satisfaction with multidisciplinary team care in rheumatology: an exploratory study. Clin Rehabil 2008;22:23-37.

8. Verhoef J, Toussaint PJ, Zwetsloot-Schonk JH, Breedveld FC, Putter H, Vlieland TP. Effectiveness of the introduction of an international classification of functioning, disability and health-based rehabilitation tool in multidisciplinary team care in patients with rheumatoid arthritis. Arthritis Rheum 2007;57:240-8.

9. Kirchberger I, Glaessel A, Stucki G, Cieza A. Validation of the comprehensive international classification of functioning, disability and health core set for rheumatoid arthritis: the perspective of physical therapists. Phys Ther 2007;87:368-84.

10. Stamm TA, Cieza A, Coenen M, Machold KP, Nell VP, Smolen JS, et al. Validating the international classification of functioning, disability and health comprehensive core set for rheumatoid arthritis from the patient perspective: a qualitative study. Arthritis Rheum 2005; 53:431-9.

11. Coenen M, Cieza A, Stamm TA, Amann E, Kollerits B, Stucki G. Validation of the International Classification of Functioning, Disability and Health (ICF) Core Set for rheumatoid arthritis from the patient perspective using focus groups. Arthritis Res Ther 2006;8:R84.

12. Terwee CB, Dekker FW, Wiersinga WM, Prummel MF, Bossuyt PM. On assessing responsiveness of health-related quality of life instruments: guidelines for instrument evaluation. Qual Life Res 2003;12:349-62.

13. Uhlig T, Lillemo S, Moe RH, Stamm T, Cieza A, Boonen A, et al. Reliability of the ICF Core Set for rheumatoid arthritis. Ann Rheum Dis 2007;66:1078-84.

14. Arnett FC, Edworthy SM, Bloch DA, McShane DJ, Fries JF, Cooper NS, et al. The American Rheumatism Association 1987 revised criteria for the classification of rheumatoid arthritis. Arthritis Rheum 1988;31:315-24. 
15. Heiberg MS, Rodevand E, Mikkelsen K, Kaufmann C, Didriksen A, Mowinckel P, et al. Adalimumab and methotrexate is more effective than adalimumab alone in patients with established rheumatoid arthritis: results from a 6-month longitudinal, observational, multicentre study. Ann Rheum Dis 2006;65:1379-83.

16. Pincus T, Summey JA, Soraci SA Jr, Wallston KA, Hummon NP. Assessment of patient satisfaction in activities of daily living using a modified stanford health assessment questionnaire. Arthritis Rheum 1983;26:1346-53.

17. Ware JE Jr, Sherbourne CD. The MOS 36-item short-form health survey (SF-36). I. Conceptual framework and item selection. Med Care 1992;30:473-83.

18. Ware JE Jr, Kosinski M, Keller SD. SF-36 physical and mental health summary scales: a user's manual. Boston, Massachusetts, USA: The Health Institute, New England Medical Center, 1994

19. Brazier J, Roberts J, Deverill M. The estimation of a preference-based measure of health from the SF-36. J Health Econ 2002;21:271-92.

20. Prevoo ML, van't Hof MA, Kuper HH, Van Leeuwen MA, van de Putte LB, van Riel PL. Modified disease activity scores that include twenty-eight-joint counts. Development and validation in a prospective longitudinal study of patients with rheumatoid arthritis. Arthritis Rheum 1995;38:44-8.

21. Fransen J, van Riel PL. The Disease Activity Score and the EULAR response criteria. Clin Exp Rheumatol 2005;23(Suppl 39):S93-9.

22. Husted JA, Cook RJ, Farewell VT, Gladman DD. Methods for assessing responsiveness: a critical review and recommendations. J Clin Epidemiol 2000;53:459-68.

23. Cohen J. Statistical power analysis for the behavioural sciences, 2nd edn. Hillsdale, New Jersey, USA: Lawrence Erlbaum Associates, 1988.

24. Middel B, van SE. Statistical significant change versus relevant or important change in (quasi) experimental design: some conceptual and methodological problems in estimating magnitude of intervention-related change in health services research. Int J Integr Care 2002;2:e15.

25. Stucki G, Liang MH, Fossel AH, Katz JN. Relative responsiveness of conditionspecific and generic health status measures in degenerative lumbar spinal stenosis. J Clin Epidemiol 1995;48:1369-78.

26. Kvien TK, Heiberg T, Hagen KB. Minimal clinically important improvement/difference (MCII/MCID) and patient acceptable symptom state (PASS): what do these concepts mean? Ann Rheum Dis 2007;66(Suppl 3):iii40-1.

27. Wells GA, Tugwell P, Kraag GR, Baker PR, Groh J, Redelmeier DA. Minimum important difference between patients with rheumatoid arthritis: the patient's perspective. J Rheumatol 1993;20:557-60.

28. Strand V, Scott DL, Emery P, Kalden JR, Smolen JS, Cannon GW, et al. Physical function and health related quality of life: analysis of 2-year data from randomized, controlled studies of leflunomide, sulfasalazine, or methotrexate in patients with active rheumatoid arthritis. J Rheumatol 2005;32:590-601.

29. Xie F, Lo NN, Lee HP, Cieza A, Li SC. Validation of the Comprehensive ICF Core Set for osteoarthritis $(\mathrm{OA})$ in patients with knee OA: a Singaporean perspective. J Rheumatol 2007;34:2301-7.

30. Beaton DE, Bombardier C, Katz JN, Wright JG. A taxonomy for responsiveness. $J$ Clin Epidemiol 2001;54:1204-17.

31. Guyatt GH, Norman GR, Juniper EF, Griffith LE. A critical look at transition ratings. $J$ Clin Epidemiol 2002;55:900-8.

32. Uhlig T, Kvien TK, Jensen JL, Axéll T. Sicca symptoms, saliva and tear production, and disease variables in 636 patients with rheumatoid arthritis. Ann Rheum Dis 1999;58:415-22.

33. Smolen JS, Aletaha D, Koeller M, Weisman MH, Emery P. New therapies for treatment of rheumatoid arthritis. Lancet 2007;370:1861-74.

\section{Access the latest content chosen by our Editors}

BMJ Journals editors select an article from each issue to be made free online immediately on publication. Other material is free after 12 months to non-subscribers. Access the Editor's Choice from the home page-or expand your horizons and see what the other BMJ Journals editors have chosen by following the links on any BMJ Journal home page. 


\section{ARD}

\section{Responsiveness of the International Classification of Functioning, Disability and Health (ICF) Core Set for rheumatoid arthritis}

T Uhlig, R Moe, S Reinsberg, et al.

Ann Rheum Dis 2009 68: 879-884 originally published online July 14, 2008

doi: 10.1136/ard.2008.088708

Updated information and services can be found at:

http://ard.bmj.com/content/68/6/879.full.html

These include:

References This article cites 30 articles, 8 of which can be accessed free at: http://ard.bmj.com/content/68/6/879.full.html\#ref-list-1

Article cited in:

http://ard.bmj.com/content/68/6/879.full.html\#related-urls

Email alerting Receive free email alerts when new articles cite this article. Sign up in service the box at the top right corner of the online article.

Topic Articles on similar topics can be found in the following collections Collections
Connective tissue disease (3178 articles)
Degenerative joint disease (3439 articles)
Immunology (including allergy) (3758 articles)
Musculoskeletal syndromes (3689 articles)
Rheumatoid arthritis (2407 articles)
Biological agents (384 articles)
Drugs: musculoskeletal and joint diseases (514 articles)

\section{Notes}

To request permissions go to:

http://group.bmj.com/group/rights-licensing/permissions

To order reprints go to:

http://journals.bmj.com/cgi/reprintform

To subscribe to BMJ go to:

http://group.bmj.com/subscribe/ 